\title{
Recurrent Anaplastic Ependymoma
}

National Cancer Institute

\section{Source}

National Cancer Institute. Recurrent Anaplastic Ependymoma. NCI Thesaurus. Code C160912.

The reemergence of anaplastic ependymoma after a period of remission. 